\title{
Personalidad Jurídica Independiente de la Sociedad Por Acciones Simplificada y Responsabilidad Limitada de sus Accionistas.
}

\author{
Independent Legal Personality of the Simplified Joint \\ Stock Company and Limited Liability of its Shareholders
}

\author{
Msc. Esteban Ortiz Mena* \\ Superintendencia de Compañías, Valores y Seguros, Ecuador \\ LLM. Paúl Noboa Velasco** \\ Superintendencia de Compañías, Valores y Seguros, Ecuador. \\ Infomación del Artículo \\ Original - Ruptura, 2020 \\ Artículo recibido / Received: 11 de octubre, 2020 \\ Artículo aceptado / Accepted: 11 de diciembre, 2020
}

* Abogado por la Pontificia Universidad Católica del Ecuador. Estudios de postgrado realizados en la Universidad Andina Simón Bolívar y la Universidad de Salamanca. Ha participado en la elaboración de los proyectos legislativos de reconocimiento de la Sociedad por Acciones Simplificada, Empresas BIC, entre otros. Fue profesor universitario de derecho mercantil y societario. También es representante del Ecuador ante la OEA como Punto Focal para el desarrollo de la Ley modelo sobre Sociedad por Acciones Simplificada. Actualmente ocupa el cargo de Intendente de Compañías de Quito. Correo electrónico: eortizme@supercias.gob.ec

** Abogado por la Pontificia Universidad Católica del Ecuador, graduado como el mejor egresado de su promoción. Tiene un LLM por University College London (UCL), título obtenido con Distinción. Actualmente labora en la Superintendencia de Compañías, Valores y Seguros, en donde centra su práctica profesional en regulación societaria y concursal. Ha participado, activamente, en varios proyectos de desarrollo normativo en derecho societario, gobierno corporativo y procesos concursales. En el ámbito académico, es Research Associate del Instituto Iberoamericano de Derecho y Finanzas. Correo electrónico: ponoboa@supercias.gob.ec 
Personalidad Jurídica Independiente

de la Sociedad Por Acciones Simplificada y

Responsabilidad Limitada de sus Accionistas

\section{Citación}

Ortiz, E. y Noboa, P. (2020). Personalidad Jurídica Independiente de la Sociedad por Acciones Simplificada y Responsabilidad Limitada de sus Accionistas. Revista Ruptura de la Asociación Escuela de Derecho PUCE. Edición 2020, p (589-620).

DOI: $10.26807 /$ rr.vi02.35

Resumen: En comparación con el excesivamente formal y rígido marco normativo de las especies societarias tradicionales, la Sociedad por Acciones Simplificadas (SAS) coadyuvará a fomentar el emprendimiento en Ecuador y a formalizar negocios otrora manejados informalmente. Debido a su flexibilidad, las SAS son formas asociativas que resultan idóneas para captar inversiones, gestionando adecuadamente el riesgo empresarial mediante estructuras determinadas de acuerdo con las necesidades operacionales de los inversionistas. Bajo aquel contexto, cabe señalar que la sociedad por acciones simplificada, al igual que cualquier sociedad mercantil, es un centro de imputación diferenciado, dotado de personalidad jurídica independiente de sus asociados. Por otro lado, los accionistas de una sociedad por acciones simplificada, cobijados por el principio de responsabilidad limitada, solamente comprometerán su patrimonio personal al monto de su aportación. Los antedichos principios son los pilares fundamentales del Derecho Societario.

Palabras clave: Responsabilidad limitada, separación patrimonial, derecho societario, emprendimiento

Abstract: The Ecuadorian Entrepreneurship and Innovation Act became into force on February 28th, 2020. Among other aspects, the mentioned Act recognizes an innovative business structure in Ecuador: the Simplified Share Companies. This modern business structure (which, incidentally, is the Ecuadorian equivalent to the British private companies, the French "Société par actions simplifiée" or the American Limited Liability Companies) is characterized by the abolition of obsolete requirements for its incorporation and legal extinction. Besides, the Entrepreneurship and Innovation Act has established a combination of 
contractual flexibility and simplified corporate rules to determine the internal structure of the company, for the benefit of its shareholders. For these reasons, the Simplified Share Companies, considered by Aurelio Gurrea-Martínez authors as a paradigm of legal innovation, will undoubtedly revolutionize the Ecuadorian corporate legal framework. That said, the Ecuadorian Simplified Share Companies have all the essential elements of the business corporations: Legal personality and limited liability. This essay will discuss those features.

Keywords: Limited liability, separate legal personality, corporate law, entrepreneurship

\section{Introducción}

Las sociedades por acciones simplificadas (en adelante, SAS) surgieron debido a que la realidad empresarial requería de figuras mucho más versátiles para hacer negocios (Velazco, Mena, 2020). La necesidad de proveer a los inversionistas privados de una figura flexible y dispositiva que mejor se adecuare a sus necesidades operacionales no se compadecía con las compañías tradicionales existentes, las cuales, debido a su imperativismo normativo y rigidez estructural, no estaban en sintonía con esta realidad mercantil. De esta manera, en contraposición a dichas anacrónicas figuras, aparece la SAS como una forma asociativa moderna que se caracteriza, entre otras bondades, por conjugar la amplísima libertad contractual propia de las sociedades personalistas con las ventajas de la limitación de responsabilidad y de financiamiento, propia de las sociedades de capital (Reyes, 2018, p.29). Bajo aquel contexto, la supresión de barreras de entrada para la constitución de sociedades mercantiles, la erradicación del imperativismo normativo y la libertad contractual son las principales características de esta novedosa especie societaria.

Bajo aquel contexto, cabe señalar que la sociedad por acciones simplificada, al igual que cualquier sociedad mercantil, es un centro de imputación diferenciado, dotado de personalidad jurídica independiente de sus asociados. Por otro lado, sus accionistas, bajo el principio de responsabilidad limitada, solamente comprometerán 
su patrimonio personal hasta el monto de su aportación al capital social. Los antedichos atributos son los pilares fundamentales del Derecho Societario.

\section{Personalidad jurídica independiente de la SAS}

De acuerdo con el profesor Aurelio Gurrea Martínez (2018), el Derecho, además de actuar como un instrumento de tutela de los derechos y libertades de los ciudadanos, es también un poderoso mecanismo para fomentar el progreso y el crecimiento económico de las sociedades. Por este motivo, los diversos ordenamientos jurídicos, con la finalidad de fomentar el desarrollo de actividades empresariales, reconocen la existencia de centros de imputación diferenciados, dotados de personalidad jurídica independiente y separada de los patrimonios generales de las personas involucradas (Carmigniani, 2004).

Dentro de aquel marco conceptual, cuando una SAS culmina su proceso formal de constitución adquiere, por reconocimiento legal, personalidad jurídica independiente de sus accionistas. En otras palabras, una SAS y, en general, cualquier sociedad mercantil (Noboa, 2018), es, en estricto rigor jurídico, un centro de imputación diferenciado de quienes se asocian bajo su manto (Andrade, 2010). El principio de independencia de la personalidad societaria ha sido expresamente reconocido en varios pasajes del ordenamiento societario del Ecuador. Por ejemplo, de acuerdo con el artículo innumerado titulado "personalidad jurídica" de la sección que la reconoce, "la sociedad por acciones simplificada, una vez inscrita en el Registro de Sociedades de la Superintendencia de Compañías, Valores y Seguros, formará una persona jurídica distinta de sus accionistas". Por su parte, la Disposición General Tercera de la Ley de Compañías, en su primer inciso, determina que una compañía "goza de personalidad jurídica propia, y en consecuencia, constituye un sujeto de derecho distinto a sus socios". El principio de autonomía de la personalidad social ha sido también ratificado por el artículo 1957, segundo inciso, del Código Civil, que textualmente señala que la sociedad "forma una persona jurídica, distinta de los socios individualmente considerados". Los artículos transcritos demuestran que, en estricto rigor 
normativo, una compañía es un ente dotado de personalidad jurídica independiente de sus socios o accionistas.

En este contexto, consideramos pertinente aclarar que una compañía incorporada de acuerdo con el ordenamiento societario de un Estado extranjero también debería ser reconocida como una persona jurídica independiente. Como leading case en la materia, encontramos al caso Arab Monetary Fund. En aquel caso, la House of Lords del Reino Unido concluyó que Arab Monetary Fund, una persona jurídica incorporada bajo el imperio de la legislación de los Emiratos Árabes Unidos, constituye un centro de imputación diferenciado de sus constituyentes, y, por consiguiente, con plena capacidad de iniciar acciones judiciales en su propio nombre. En palabras de Lord Templeman, "in the present case the Fund was given legal personality and capacity by the law of the state wherein it has its seat or permanent location. There is every reason why the Fund should be recognised as a legal personality by the courts of the United Kingdom and no reason whatsoever why recognition should be withheld" (Arab Monetary Fund v. Hashim (No. 3) 1991).

Lógicamente, el principio de autonomía de la personalidad societaria también presupone que la compañía, como un centro de imputación diferenciado, es una persona jurídica independiente de quienes la administran o representan. Este principio encuentra sustento legislativo en el artículo 255 de la Ley de Compañías, aplicable sobre las sociedades anónimas y, por consiguiente, sobre las SAS por expreso reenvío normativo. Concretamente, el referido artículo, en su segundo inciso, establece que "los administradores no contraen por razón de su administración ninguna obligación personal por los negocios de la compañía.” El profesor Guillermo Cabanellas (1993) define al término personalidad como "la aptitud legal para ser sujeto de derechos y obligaciones". Partiendo de esta definición, la personalidad jurídica independiente es el principio que habilita a una SAS y, en general, a cualquier persona jurídica, a tener una voluntad propia, a ejercer derechos y contraer obligaciones a título personal. Es decir, como derivación del referido principio, la facultad que adquiere una sociedad es empleada para su plena actuación erga omnes y para adquirir responsabilidades frente a terceros. Por eso, el patrimonio de 
una SAS es distinto del patrimonio del individuo o grupo de personas que la constituyeron.

En cuanto a los derechos y las obligaciones de las sociedades, el autor José Ignacio Narváez García (1999) señala que:

En ese contexto, la sociedad -persona jurídica- corresponde a ese orden institucional del que se derivan consecuencias prácticas, a saber: a) los bienes de la persona jurídica no pertenecen en común a sus miembros sino que integran su propio patrimonio; b) los acreedores de los asociados no tienen derecho alguno sobre los bienes sociales; c) la persona jurídica adquiere derechos y contrae obligaciones y, a pesar de carecer de vocación para heredar, puede recibir bienes por disposición testamentaria (...).

Sobre este mismo punto, Santiago Andrade Ubidia (s.f), ex Magistrado de la ahora Corte Nacional de Justicia, coincide en que

nadie duda que el reconocimiento de la personalidad jurídica a entes asociativos distintos de los seres humanos, ha sido trascendental para el desarrollo de la economía y del derecho y para que, en la actualidad, pueda funcionar una economía de libre mercado. No obstante, las diversas teorías sobre la naturaleza jurídica de estos entes asociativos, aun las que les niegan la calidad de personas, les reconocen su capacidad de adquirir derechos y obligaciones per ser ipsum, lo que en definitiva constituye la esencia de la personalidad en el ámbito del derecho.

Justamente, existen varios aspectos que se derivan del principio de la personalidad jurídica independiente de la SAS. En primer lugar, será esta paradigmática especie societaria, y no sus accionistas, la persona responsable por las obligaciones sociales (Ferran, Chan Ho, 2014). Bajo este esquema, el patrimonio social está destinado a satisfacer los créditos de los acreedores sociales, mientras que los bienes personales de los accionistas están reservados para sus acreedores personales; y, por regla general, los acreedores sociales no cuentan con la posibilidad de perseguir los bienes personales de los accionistas. Claramente, el mencionado principio es un poderoso mecanismo que permite a los accionistas de una SAS gestionar su riesgo comercial (Ridley, 
Shepherd, 2015, p.24), debido a que ellos cuentan con la alternativa de incursionar en actividades mercantiles sin exponer su patrimonio personal (Ferran, Chan Ho, 2014). Este principio ha sido reconocido, de manera categórica, por el artículo 568, primer inciso, del Código Civil, norma de aplicación supletoria para el régimen de la SAS en Ecuador. En lo medular, este artículo estipula:

(...) y recíprocamente, las deudas de la corporación no dan a nadie derecho para demandarlas, en todo o en parte, a ninguno de los individuos que componen la corporación, ni dan acción sobre los bienes propios de ellos, sino sobre los bienes de la corporación.

En segundo término, los bienes sociales son propiedad de la SAS, como sujeto de derecho autónomo. En consecuencia, dichos bienes no pertenecen a sus accionistas. En este respecto, Lord Wrenbury (1925) concluyó lo siguiente:

My Lords, this appeal may be disposed of by saying that the incorporator even if he holds all the shares is not the corporation, and that neither he nor any creditor of the company has any property legal or equitable in the assets of the corporation

En otras palabras, la participación de una persona en el capital social de una SAS no la convierte, ipso facto, en propietaria de los bienes sociales (Gramophone and Typewriter Co Ltd v Stanley, 1908, Court of Appeal).

De la conclusión anterior se desprende que, legalmente, la propiedad de una SAS se encuentra fuera del alcance de sus socios o accionistas y, más importante, fuera del alcance de los acreedores personales de aquéllos. Dicho blindaje, denominado por Hansmann y Kraakman como "entity shielding" (Hansmann y Kraakman, 2000), ha sido reconocido, de manera categórica, por los artículos 568, primer inciso, y 2000, del Código Civil.

En lo pertinente, el primero de los referidos artículos establece, de manera textual, lo siguiente: "Lo que pertenece a una corporación, no pertenece, ni en todo ni en parte, a ninguno de los individuos que 
la componen (...)". Por su parte, el segundo artículo, en su primer inciso, determina que:

Los acreedores de un socio no tienen acción sobre los bienes que éste haya introducido a la sociedad, sino por hipoteca anterior a la sociedad o por hipoteca posterior, cuando el aporte del inmueble no conste por inscripción en el competente registro (CC, art 569).

Dicho esto, los acreedores de una sociedad por acciones simplificada solamente podrían perseguir los bienes y activos corporativos, pero no tienen derecho a iniciar un proceso en contra del patrimonio personal de los accionistas. De igual forma, el patrimonio de una sociedad por acciones simplificada no pertenecerá, ni en todo ni en parte, a sus accionistas. Como derivación de su constitución, una SAS también podría demandar y ser demandada a título personal. Al respecto, cabe reiterar que los derechos y obligaciones de una sociedad mercantil, como un centro de imputación diferenciado dotado de personalidad jurídica independiente de sus asociados, no se pueden confundir, al momento de presentar acciones en contra de la sociedad por acreencias que la misma ha adquirido, con los derechos y obligaciones atribuibles a sus socios o accionistas.

Por consiguiente, en estricto rigor procesal, los accionistas de una SAS, salvo puntuales excepciones establecidas en la Ley, no podrían ser forzados a cubrir o responder por las obligaciones sociales. Respecto a la legitimación en causa, elemento sustancial del proceso, la ex Corte Suprema de Justicia (2004) ha señalado, categóricamente, que:

para actuar como parte de un proceso, no basta ser legalmente capaz o tener poder suficiente para intervenir en juicio sino que es necesaria una condición más precisa referida al litigio de que se trata y consiste en una relación entre el sujeto y el objeto (jurídico).

Bajo aquel contexto, la legitimatio ad causam es definida como "la titularidad del derecho o relación jurídico-material objeto del juicio (Echandía, s.f). La legitimación en la causa, respecto al demandado, requiere que ésta sea "la persona que, conforme a la ley sustancial, está legitimado para oponerse o contradecir dicha pretensión del 
actor, es decir, cuando es el contradictor legítimo" (Corte Nacional de Justicia, 2004). Es decir, citando a otro pronunciamiento de la ex Corte Suprema de Justicia, no existe debida legitimación en la causa "cuando el demandante o el demandado no tenía en absoluto legitimación en la causa, por ser personas distintas a quienes correspondía formular esas pretensiones o contradecirlas" (Corte Nacional de Justicia, 2004). De acuerdo con Devis Echandía (s.f, p.286), la legitimación en la causal es personal y subjetiva. Por consiguiente, en aplicación del principio bajo análisis existiría una falta de legítimo contradictor cuando, en sede judicial, se demande a un accionista el cumplimiento de una obligación atribuible a una SAS, por cuanto la sociedad, como un patrimonio diferenciado, sería el único sujeto obligado a contradecir cualquier pretensión formulada en su contra.

En sentido contrario, la legitimación en causa respecto del actor surge cuando "este es la persona que, de acuerdo con la ley sustancial, está legitimada para solicitar sentencia de mérito o de fondo y, por tanto, se resuelva si existe o no el derecho o la relación jurídica sustancial pretendida en la demanda". Por consiguiente, y considerando que una SAS es una persona jurídica independiente de quienes la constituyeron, sus accionistas no contarían con la facultad de iniciar una acción judicial por una pretensión atribuible a la referida sociedad. De acuerdo con Foss v. Hartbottle, leading case (1843) en la materia, cuando un agravio es cometido a una compañía solamente ella cuenta con la atribución de iniciar las acciones judiciales que correspondieren, y no sus accionistas. En opinión de Wigram V-C (1843), "the only question can be whether the facts alleged in this case justify the departure from the rule which, prima facie, would require that the corporation should sue in its own name. No such justification was found".

Justamente, este ha sido el criterio de la Superintendencia de Compañías, Valores y Seguros, organismo administrativo de control societario en el Ecuador. Concretamente, la Doctrina Jurídico-Societaria No. 123 determinó que la acción de impugnación de una resolución administrativa emitida por dicho Órgano de Control solamente podrá ser efectuada por las propias compañías -por intermedio de sus representantes legales- y no por sus socios o accionistas. 
De manera textual, dicha doctrina estableció lo siguiente:

Si la compañía forma 'una persona jurídica distinta de los socios individualmente considerados', según el inciso final del artículo 1957 del Código Civil y de acuerdo a lo confirmado por el inciso séptimo del artículo 2 de la Ley de Compañías, a los socios o accionistas de las sociedades sujetas al control de la Superintendencia de Compañías, individualmente considerados, cualquiera que sea su número o el porcentaje de capital que representen, no les está permitida la facultad de apelar, objetar o impugnar válidamente la Resolución expedida por el Superintendente de Compañías -o por un Intendente- en la que se hubiere aprobado o negado un aumento de capital, una prórroga del plazo, un cambio de denominación o de domicilio y, en general, cualquiera de los actos mencionados en el artículo 33 de la Ley de Compañías y que fueren legalmente posibles para la compañía de que se trate; pues tales son actos de la sociedad correspondiente, que le pertenecen a ella por haber sido tomados por su correspondiente órgano social y por haber sido instrumentados en su nombre por su correspondiente representante legal (artículo 1464 del Código Civil). // En consecuencia, sólo las compañías -como sujetos de derecho que son- por intermedio de sus representantes legales, pueden ejercer la antedicho facultad de apelar, objetar o impugnar las resoluciones que sobre los actos aludidos hubiere dictado la Superintendencia de Compañías (...) y que afectaren a sus intereses (pues simplemente no se concibe reclamo alguno en sentido contrario, como sería el caso de la resolución aprobatorio que en nada hubiere contrariado la respectiva solicitud).

Claramente, el principio de independencia de la personalidad jurídica, en la esfera procesal, resulta indispensable con el fin de determinar cuándo una SAS tendrá el derecho a que se resuelvan ciertas pretensiones y cuando la misma será la persona llamada a contradecirlas.

En tercer lugar, cabe señalar que, con fundamento en el principio de autonomía de la personalidad social, la SAS (y, en general, cualquier persona jurídica de derecho privado), podrían ser, bajo la legislación ecuatoriana y si las circunstancias lo ameritan, penalmente responsables. A efectos de una eventual imputación penal, las personas jurídicas son consideradas por el Código Orgánico Integral Penal como un centro de imputación penal diferenciado de sus administradores 
y de las personas que las constituyeron. En otras palabras, el marco penal vigente, alejándose del principio clásico de inimputabilidad de las personas jurídicas, ha adoptado el principio societas delinquere potest (Araujo, 2014, p.63). Al respecto, cabe precisar que el Código Orgánico Integral Penal (en adelante, COIP), en el inciso primero de su artículo 49, establece lo expuesto a continuación:

En los supuestos previstos en este Código, las personas jurídicas nacionales o extranjeras de derecho privado son penalmente responsables por los delitos cometidos para beneficio propio o de sus asociados (...)

Sin ahondar en detalles respecto a la responsabilidad penal de una SAS, el segundo inciso del artículo 49 del COIP, al señalar que "la responsabilidad penal de la persona jurídica es independiente de la responsabilidad penal de las personas naturales que intervengan con sus acciones u omisiones en la comisión del delito", confirma el principio de independencia de la personalidad societaria en el Ecuador. En nuestro criterio, si una sociedad no sería un centro de imputación diferenciado de las personas que la conforman o representan, la atribución directa de responsabilidad penal sobre ella de acuerdo con el COIP devendría jurídicamente improcedente.

Finalmente, la personalidad societaria independiente de las compañías coadyuva a reducir los costos de transacción en la formación de relaciones contractuales, mismas que devendrían impracticables ante la inexistencia de esta figura (Kraakman y Hansmaan, s.f). La aplicación de este principio reduce los costos de monitoreo de los acreedores sociales, ya que ellos, debido a la existencia de un centro de imputación diferenciado capaz de obligarse por sí mismo, no deben evaluar la situación patrimonial de cada uno de los socios agrupados bajo la referida organización societaria (Kraakman y Hansmaan, 2006, p.1344).

En conclusión, como una entidad diferenciada de sus accionistas, una SAS debe ser tratada, en estricto rigor legal, como una persona independiente, con derechos y obligaciones atribuibles a sí misma. Por consiguiente, sería la SAS quien, bajo su propio nombre, celebraría contratos, adquiriría obligaciones, sería propietaria del haber 
social, podría demandar, ser demandada o, como fue indicado anteriormente, ser responsable penalmente, sin perjuicio de la eventual atribución de responsabilidad sobre sus accionistas o administradores. Esta regla general, no obstante, encuentra una excepción en la figura del levantamiento del velo societario, remedio procesal "mediante el cual resulta posible prescindir de la forma de la sociedad o asociación con que se halla revestido un grupo de personas y bienes, negando su existencia autónoma como sujeto de derecho frente a una situación jurídica particular (Ubidia citando a Dobson, s.f).

\section{Levantamiento del velo societario de la SAS}

Por regla general, una SAS es un centro de imputación diferenciado de sus accionistas. No obstante, dicha autonomía, de acuerdo con las reformas introducidas al ordenamiento societario por la LOEI, podría ser desestimada bajo ciertos supuestos. El artículo innumerado titulado "desestimación de la personalidad societaria" aplicable sobre la SAS establece, de manera textual, lo siguiente:

Cuando se utilice la sociedad por acciones simplificada en fraude a la ley o en perjuicio de terceros, los accionistas y los administradores que hubieren realizado, participado o facilitado los actos defraudatorios, responderán solidariamente por las obligaciones nacidas de tales actos y por los perjuicios causados.

La inoponibilidad de la personalidad jurídica solamente podrá declararse judicialmente, de manera alternativa, o como una de las pretensiones de un determinado juicio por colusión o mediante la correspondiente acción de inoponibilidad de la personalidad jurídica de la compañía deducida ante un juez de lo civil y mercantil del domicilio de la compañía o del lugar en que se ejecutó o celebró el acto o contrato dañoso, a elección del actor. El desvelamiento del velo societario se regirá por los artículos 17, 17A, 17B y la Disposición General Tercera de la Ley de Compañías.

Conforme fue indicado anteriormente, el principio de autonomía de la personalidad societaria produce una distinción entre el patrimonio de una SAS (y, en general, de cualquier compañía), y el patrimonio de 
sus asociados. Esto quiere decir que, en la gran mayoría de los casos, la autonomía de la personalidad jurídica de una SAS, centro de imputación diferenciado con derechos y obligaciones independientes de sus miembros, será oponible por cualquier socio o accionista que sea requerido a cumplir una obligación atribuible, de manera exclusiva, a la sociedad. Esta regla general, no obstante, encuentra una salvedad en la figura del levantamiento del velo societario. Este instrumento procesal de uso excepcional, busca penetrar en la interioridad del manto que recubre a los controlantes de una sociedad mercantil para hacerlos responsables, a título personal, de actos y comportamientos abusivos o fraudulentos.

Como señala el autor argentino Efraín Richard (2002) "nada más es correr el velo del ente personificado para conocer qué personas son las que se ocultan o actúan indebidamente detrás de ella.” En este respecto, el jurista español José Hurtado Cobles (2008), determina que el levantamiento del velo societario no es más que "aquella técnica judicial que permite adentrarnos en el seno de la persona jurídica para poder desvelar cualquier posible fraude o abuso que se haya podido cometer sobre la base de ésta”.

De acuerdo con la legislación ecuatoriana, la inoponibilidad de la personalidad jurídica de una sociedad por acciones simplificada se regirá a lo dispuesto, entre otros, en el artículo 17 de la Ley de Compañías ${ }^{1}$. El artículo referido, en su inciso primero, claramente establece que por los fraudes, abusos o vías de hecho, que se cometan a nombre de compañías y otras personas naturales o jurídicas, serán personal y solidariamente responsables: (i) Quienes los ordenaren o ejecutaren. (ii) Los que obtuvieren provecho, hasta lo que éste valga; y, (iii) Los tenedores de los bienes, solamente para efectos de la restitución. Por lo tanto, la inoponibilidad de la personalidad jurídica, en estricto rigor legal, solamente se puede invocar cuando se cometiere, a nombre de una SAS, un acto fraudulento, abusivo o concurra una vía de hecho.

1 Reformado por la Ley Orgánica de Fortalecimiento y Optimización del Sector Societario y Bursátil, publicada en el Registro Oficial No 249 del 20 de mayo de 2014. 
El fraude a terceros ha sido definido "como el malicioso y desleal obrar en perjuicio ajeno en el cual asoma, agravada, la figura de la mala fe en sentido objetivo". En este respecto, Alessandri, Somarriva y Vodanovic (s.f) consideran que el fraude difiere del dolo "porque el último tiene lugar entre las partes cuando una de ellas se vale de engaño para perjudicar a la otra; en cambio, el fraude es una maniobra de mala fe ejecutada por una o ambas partes dirigida a perjudicar a terceros". Por su parte, el fraude a la ley concurre cuando "la voluntad del particular, respetando aparentemente la ley, la viola; lo cual ocurre cuando una persona se comporta de modo que el negocio, respetando la letra de la ley, llega a violarla en su espíritu" (Salgado Valdez, 2015). En nuestro criterio, las figuras del fraude a terceros y fraude a la ley, bajo el marco sugerido, darían lugar al levantamiento del velo societario en desmedro de los accionistas de una SAS.

De acuerdo con el artículo innumerado agregado a continuación del artículo 36 del Código Civil, "constituye abuso del derecho cuando su titular excede irrazonablemente y de modo manifiesto sus límites, de tal suerte que se perviertan o se desvíen, deliberada y voluntariamente, los fines del ordenamiento jurídico".

Al respecto, el doctor Roberto Salgado Valdez considera que las vías de hecho son "los caminos y procedimientos que adopta una compañía sin atenerse a los caminos y procedimientos que establecen las leyes o los contratos" (Salgado, 2015, p.467).

En definitiva, la inoponibilidad de la personalidad jurídica es un concepto que responde a una sucesión de abusos y fraudes cometidos por intermedio de la forma societaria, bajo la protección patrimonial otorgada por la personalidad autónoma de las sociedades mercantiles. En palabras de José Ignacio Narváez García (1999): "El ente hermético se abre siempre que surja o se perciba un asomo de mala fe, fraude, abuso del derecho o simulación" (p.41). Es por esta razón que, por ejemplo, una mera infracapitalización no podría ser justificación suficiente para levantar el velo societario y atribuir, por este mero hecho, responsabilidad directa sobre los asociados.

Al respecto, Francisco Reyes Villamizar (2019) ha establecido que: 
los tribunales norteamericanos se han negado, en forma reiterada, a desconocer la separación patrimonial propia de la personificación jurídica de la compañía, cuando el único fundamento que se aduce es que la sociedad se constituyó sin el capital que se requería para hacerle frente a sus obligaciones, dada la naturaleza y dimensión de la empresa social. A pesar de estimarse que la infracapitalización no constituye base suficiente para levantar el velo societario, la carencia de capital, sumada a alguno de los factores ya indicados (como, por ejemplo, la concurrencia de fraude), puede servir de fundamento para aplicar la teoría (p.315-316).

Por consiguiente, la personalidad jurídica de las sociedades mercantiles deberá ser desconocida por los tribunales de justicia cuando la forma societaria sea, citando a Prat Rubi (1985), "invocada para fines contrarios a derecho". En consecuencia, se entiende que la única razón para desestimar la personalidad jurídica de una SAS y así afincar la responsabilidad civil sobre sus accionistas, sería la utilización de la misma para alcanzar proditorios fines, mediante la realización o ejecución de actos contrarios a la Ley. En definitiva, el levantamiento del velo societario es una figura procesal que cumple la función de brindar una solución frente a comportamientos fraudulentos o abusivos. Al respecto, Seijas Renjifo (2007) señala, acerca del levantamiento del velo societario, que "resulta pertinente su aplicación cuando la persona jurídica es utilizada en contra de los intereses superiores de la sociedad o por motivo de conflictos externos o internos".

El levantamiento del velo societario solamente puede ser declarado, dentro de un debido proceso, en sede judicial. El artículo 17 de la Ley de Compañías, en su inciso tercero, habla claramente sobre la jurisdicción de la inoponibilidad y dice, en lo pertinente, que esta orden "solamente podrá declararse judicialmente (...)." Por lo tanto, es potestad exclusiva de los órganos jurisdiccionales, luego del análisis a que someta la situación específica que se le plantee, ordenar que se rompa o levante el velo societario, cuando se hubiere determinado que la forma societaria fue utilizada para alcanzar proditorios fines. El procedimiento que se aplicará en este caso, de acuerdo con el artículo 17A de la Ley de Compañías, será el ordinario. Finalmente, cabe precisar que, según el artículo 17B de la Ley de Compañías, la acción del corrimiento del velo societario prescribirá en seis años contados 
a partir del hecho correspondiente, si hubiere sido uno solo, o del último de ellos, si hubieren sido varios.

Esta herramienta procesal constituye un régimen de excepción que se deriva de la necesidad de alcanzar la verdad real cuando la forma societaria fuere utilizada como una fachada para encubrir un fraude a la ley o un abuso del derecho. Debido a su naturaleza eminentemente excepcional, su aplicación devendrá improcedente cuando existiere otra vía para remediar la situación anómala advertida, como una eventual orden de disolución societaria de la compañía por una desviación de su finalidad societaria o una eventual nulidad del acto constitutivo por objeto o causa ilícita. En adición, su carácter excepcional encontraría sustento en la necesidad de evitar un escenario de incertidumbre societario que atenten contra la naturaleza misma del Derecho de Sociedades. Es, justamente, por este motivo, que connotados autores societarios como Stephen Bainbridge (2000) consideran que la figura del levantamiento del velo societario debe ser abolida. Concretamente, el mencionado autor ha señalado lo siguiente:

The standards by which veil piercing is effected are vague, leaving judges great discretion. The result has been uncertainty and lack of predictability, increasing transaction costs for small businesses. At the same time, however, there is no evidence that veil piercing has been rigorously applied to effect socially beneficial policy outcomes. Judges typically seem to be concerned more with the facts and equities of the specific case at bar than with the implications of personal shareholder liability for society at large. Veil piercing thus has costs, but no social pay-off.

A decir de Hannigan, los socios o accionistas de una compañía tienen la legítima expectativa de asumir, en términos normales, que la autonomía de la personalidad societaria será respetada y que ellos continuarán cobijados por el manto societario.

Para Brenda Hannigan (2016), ni siquiera se podrá confundir la figura para el cobro de créditos tributarios o de índole laboral. La misma ley establece que "salvo que, en sede judicial, se hubiere desestimado la personalidad jurídica de la sociedad por acciones simplificada, el o los accionistas no serán responsables por las obligaciones 
laborales, tributarias o de cualquier otra naturaleza en las que incurra la sociedad". Esta disposición reafirma la figura de la personalidad propia de la SAS y la separación clara y precisa de patrimonios entre la persona jurídica y sus accionistas o administradores. Esta es una disposición que no admite duda.

El empleo de esta figura debe ser analizado con extremo cuidado, debiendo evitarse su aplicación a la ligera en contra de socios o accionistas que han cumplido con la Ley y obrado conforme a Derecho (Boldó, 2000, p.77). Por consiguiente, el velo societario que cobija a los accionistas de una SAS deberá ser respetado en todo momento, salvo que se constatare, en sede judicial, que la sociedad fue constituida o utilizada, en perjuicio de terceros, con fines fraudulentos o abusivos para encubrir la consecución de proditorios fines. Asimismo, esta distinción deberá ser inoponible cuando se comprobare, judicialmente, que la forma societaria fue utilizada como un mero recurso formal para evadir alguna exigencia o prohibición legal, mediante una simulación contractual o por cualquier otra vía de hecho semejante, siempre que de ello se derivaren perjuicios a terceros. En aquellos escenarios, quienes hubieren realizado, facilitado, participado en dichos actos, o se beneficiaren indebidamente de su consumación, serán directa y personalmente responsables por las obligaciones derivadas de los mismos. Dentro de los sujetos pasivos de esta responsabilidad encontramos, lógicamente, a los accionistas y a los administradores de una SAS.

Una reciente sentencia de la Corte Constitucional del Ecuador (Sentencia No. 22-13-IN/20), que tenía por objeto analizar la constitucionalidad por el fondo y por la forma de varios artículos de la Ley Orgánica de Defensa de los Derechos Laborales, confirmó que el levantamiento del velo societario siempre deberá ser ordenado en sede judicial, "dentro de una acción de develamiento societario o dentro de otro proceso jurisdiccional alternativo que permita corregir el abuso de derecho en el uso de la personalidad jurídica (...)" Concretamente, el artículo 1 de la Ley Orgánica para la Defensa de los Derechos Laborales - acertadamente derogado por la Ley Orgánica para el Fomento Productivo, Atracción de Inversiones, Generación de Empleo, y Estabilidad y Equilibrio Fiscal-, en lo pertinente 
dictaminaba que las "instituciones del Estado que por ley tienen jurisdicción coactiva”, ante un abuso de la personalidad jurídica, podían llegar hasta el último nivel de propiedad, que siempre recaía sobre personas naturales. Este artículo -a nuestro juicio indebidamente- abarcaba a los socios o accionistas de una compañía, quienes debían responder con todo su patrimonio por las acreencias antes referidas, en caso que los jueces de coactivas o las autoridades de trabajo, en ejercicio de sus atribuciones, hubieren llegado a determinar que la forma societaria fue utilizada, fraudulentamente, para burlar el cobro de sus acreencias (Noboa, 2018).

La concesión normativa de esta facultad a los jueces de coactivas y a las autoridades del trabajo era absolutamente inapropiada (Noboa, 2018). De acuerdo con Lorenzo Álvarez de Toledo (1997, p.18-22):

en ningún caso se debe atribuir a las autoridades administrativas, ni siquiera las de control, la atribución de aplicar esta teoría, porque se estaría violando las garantías del debido proceso y atropellando el derecho de los involucrados, quienes únicamente en virtud de una resolución judicial pueden ser privados de sus derechos y condenados a realizar una prestación más allá de su privilegio de exclusión de responsabilidad.

De este modo, y con fundamento en la naturaleza excepcional de la acción de develamiento societario, la Corte Constitucional del Ecuador, de manera muy apropiada, concluyó lo siguiente:

En atención a su excepcionalidad y al sumo cuidado que su análisis exige, la desestimación de la personalidad jurídica no puede ser conocida y resuelta dentro de un procedimiento coactivo, dado que su naturaleza de cobro ágil de créditos no permite el nivel de debate que esta cuestión necesita, ni ofrece garantías suficientes para que tanto la persona jurídica en cuestión como sus socios o accionistas puedan presentar alegatos y pruebas de descargo en el momento oportuno y en igualdad de condiciones; es decir, el procedimiento coactivo no es un procedimiento idóneo para que los intervinientes en un develamiento societario puedan ejercer su derecho a la defensa de manera oportuna y en igualdad de condiciones (Corte Constitucional del Ecuador, Sentencia No. 22-13-IN/20, p. 69.) 
Justamente, una orden directa de levantamiento del velo societario por autoridades del trabajo o de coactivas, al desconocer el principio de separación patrimonial entre las compañías y sus asociados, podría atentar contra el principio constitucional de seguridad jurídica y los derechos a la defensa y de propiedad de quienes, de buena fe, están cobijados por el manto societario.

De manera muy apropiada, la Corte Constitucional del Ecuador determinó que:

El derecho a la defensa podría a priori verse afectado por una participación tardía en el procedimiento por parte del destinatario de una medida impuesta al amparo del artículo 1 de la LODDL. Pero como hemos comentado en líneas precedentes, la imposición de dichas medidas será acorde al derecho a la defensa y a la seguridad jurídica, si la autoridad acude previamente a los mecanismos jurisdiccionales idóneos para la determinación del fraude o abuso de derecho en el contrato de sociedad. De tal modo, se debe excitar y/o impulsar el proceso de levantamiento de velo societario y otras vías jurisdiccionales alternativas que permitan determinar el carácter excepcional que nuestro ordenamiento jurídico exige para la inoponibilidad de la personalidad jurídica, en un caso concreto. Al contrario, un develamiento societario efectuado directamente por el empleado recaudador coactivo, prescindiendo de dichos procesos judiciales idóneos para determinación de las causas que lo justifican, sería contrario al derecho a la defensa y a la seguridad jurídica. "Bajo idénticos argumentos que los señalados en el acápite anterior, si la autoridad emitiera tales medidas - omitiendo el proceso de levantamiento societario u otros procesos judiciales alternativos en los términos indicados anteriormente - dicha actuación sería además contraria al derecho a la propiedad, ya que se atentaría a la certeza de los contratos de sociedad efectuados de buena fe, desdibujando sin justificación legítima la diferencia de patrimonios entre el socio o accionista con la persona jurídica a la que pertenecen, dejando de ser centros de imputación autónomos. En consecuencia, la emisión de medidas descritas en el artículo 1 de la LODDL en contra de bienes de socios o accionistas será acorde a la Constitución siempre y cuando se haya obtenido previamente un pronunciamiento judicial que permita el develamiento societario, de acuerdo al procedimiento regulador por el legislador para ello. (Corte Constitucional del Ecuador, Sentencia No. 22-13-IN/20, 70.) 
Por todos estos elementos, consideramos que la mencionada sentencia, muy apropiada y absolutamente fundamentada, clarifica el carácter excepcional de las acciones de develamiento societario.

Con esta ligera digresión, y para finalizar este análisis, cabe precisar que las reformas a la Ley de Compañías introducidas por la LOEI contemplan, respecto a las consecuencias de la desestimación de la personalidad jurídica de una SAS, una diferencia fundamental frente a los parámetros previstos en el artículo 17 de la Ley de Compañías. En adición de la extensión de responsabilidad a quienes hubieren utilizado la forma societaria abusiva o fraudulentamente, la regulación normativa de la SAS en Ecuador permite requerir, adicionalmente, una indemnización por los perjuicios irrogados en contra de quienes hubieren perpetrado los actos defraudatorios por intermedio de esta especie societaria. En palabras de Reyes Villamizar (2018, p. 48):

aparte de la extensión de responsabilidad a los accionistas que controlen (que es la consecuencia básica de cualquier sistema de desestimación), puede intentarse, adicionalmente, una indemnización de perjuicios en contra de accionistas y administradores por los actos defraudatorios que hubieren dado lugar a la perforación del velo y a la consecuente extensión de responsabilidad.

\section{Principio de responsabilidad limitada de los accionistas}

El principio de responsabilidad limitada de los socios o accionistas es el segundo pilar fundamental del Derecho Societario. De conformidad con el mencionado principio, la responsabilidad de los socios o accionistas está limitada al monto de sus aportaciones (Davies, Worthington, Gower, Davies, 2012). El principio de responsabilidad limitada crea una cláusula implícita entre la compañía y sus acreedores sociales, a través de la cual los últimos tienen el derecho de perseguir el patrimonio social, pero se encuentran impedidos de iniciar acción alguna contra el patrimonio personal de los socios o accionistas (Kraakman, 2004). 
En otras palabras, el principio de responsabilidad limitada blinda a los socios o accionistas de responsabilidad personal por las obligaciones sociales, debido a que los mismos (salvo las puntuales excepciones previstas en la Ley) no deben contribuir más allá del monto de su aportación social (Ferran y Chan Ho, s.f). Este principio ha sido reconocido, de manera categórica, por el artículo 568, primer inciso, del Código Civil. En lo medular, aquel artículo dictamina lo siguiente:

(...) y recíprocamente, las deudas de la corporación no dan a nadie derecho para demandarlas, en todo o en parte, a ninguno de los individuos que componen la corporación, ni dan acción sobre los bienes propios de ellos, sino sobre los bienes de la corporación.

La LOEI, en las normas reformatorias a la Ley de Compañías sobre SAS (concretamente, en su capítulo Disposiciones Generales), ha reconocido el principio de limitación de responsabilidad de los accionistas de una SAS, al establecer, textualmente en su artículo segundo, que:

La sociedad por acciones simplificada podrá constituirse por una o varias personas naturales o jurídicas, quienes sólo serán responsables limitadamente por las obligaciones de la sociedad por acciones simplificada hasta por el monto de sus respectivos aportes.

Dicho esto, cabe señalar que el principio de responsabilidad limitada ha sido establecido en beneficio de los socios o accionistas de una compañía, más no en favor de la compañía per se. Conforme fue indicado anteriormente, una sociedad mercantil, como derivación del principio de autonomía de la personalidad social, es el sujeto jurídicamente obligado a cumplir con la totalidad de sus obligaciones. Por esta razón, una compañía mal podría invocar el principio de responsabilidad limitada para eludir el cumplimiento de las obligaciones que la misma, durante su marcha operacional, hubiere adquirido de manera directa. Habiendo aclarado aquello, reiteramos que los socios o accionistas son quienes ven limitada su responsabilidad personal, por una eventual concurrencia de obligaciones sociales insatisfechas, hasta el monto de sus aportaciones. Por este motivo, 
ambos principios, a pesar de estar generalmente concatenados, no son equivalentes, ya que el alcance de cada uno de ellos es distinto (Blumberg, 1993, p.19).

La Ley de Compañías del Ecuador contiene disposiciones que diferencian ambos principios. Según el artículo 74 de la referida Ley:

todos los socios colectivos y los socios comanditados estarán sujetos a responsabilidad solidaria e ilimitada por todos los actos que ejecutaren ellos o cualquiera de ellos bajo la razón social, siempre que la persona que los ejecutare estuviere autorizada para obrar por la compañía.

Con fundamento en dicho artículo, es claro que, bajo la Ley de Compañías, pueden existir compañías con personalidad social autónoma sin limitación de la responsabilidad patrimonial de los asociados. En otras palabras, la responsabilidad limitada no siempre confluirá con la personalidad autónoma de una sociedad mercantil.

Con esta ligera digresión, debemos resaltar que la limitación de la responsabilidad de los socios o accionistas, privilegio patrimonial de trascendental importancia para el fomento del emprendimiento y la innovación, tiene una serie de positivas características. En primer lugar, el principio de responsabilidad limitada fomenta las actividades productivas (Ferran y Chan Ho, s.f), ya que permite a los emprendedores e innovadores asumir riesgos empresariales e iniciar nuevos negocios sin exponer su patrimonio personal ante eventuales riesgos que podrían derivarse de la marcha operacional de la sociedad (Muscat, 1996, p.163).

Con fundamento en los beneficios del principio de responsabilidad limitada, Nicholas Murray Butler, Premio Nobel de la Paz y Presidente de la Universidad de Columbia, llegó a afirmar que la sociedad de responsabilidad limitada es el descubrimiento más importante de la época contemporánea. Textualmente, sus palabras fueron las siguientes (2011): "The limited liability corporation is the greatest single discovery of modern times. Even steam and electricity are less important than the limited liability company". 
En segundo término, este principio fomenta una diversificación en la propiedad de las acciones (portfolio diversification en palabras de Ferran y Chan Ho). Debido a la limitación de su responsabilidad personal, un inversionista contaría con mayores incentivos para ampliar su cartera de acciones, ya que él no se vería expuesto a asumir la totalidad de las obligaciones de cada una de las compañías emisoras de las acciones de su propiedad.

En tercer lugar, el principio de responsabilidad limitada reduce los costos de investigación por parte de los acreedores sociales cuando contraten con la compañía (Gurrea, 2019), particularmente por los siguientes motivos: (i) un acreedor de una compañía, con fundamento en este principio, solamente deberá evaluar la solvencia patrimonial de la compañía y no la de sus socios o accionistas (Ferran y Chan Ho, s.f), por cuanto ellos, en aplicación del principio analizado, no podrán ser obligados a cubrir deudas impagas de la compañía con su patrimonio personal. (ii) un acreedor social, cuando correspondiere, solamente podrá demandar el cumplimiento de una obligación contractual a la compañía, pero no a sus socios o accionistas (Ferran y Chan Ho, s.f). Claramente, una reducción en los costos de investigación de los acreedores sociales podría ocasionar un impacto positivo en los términos bajo los cuales una compañía adquiere capital de deuda (Ferran y Chan Ho, s.f).

Finalmente, el principio de responsabilidad limitada facilita una inversión societaria pasiva, la cual se caracteriza en la concesión de financiamiento sin la necesidad de participar o monitorear la administración de la compañía (Ferran y Chan Ho, s.f). Debido a la inexistencia de responsabilidad ilimitada por las obligaciones sociales, los inversionistas no tienen la necesidad imperativa de vigilar constantemente la marcha administrativa de las compañías, lo cual, en palabras de Aurelio Gurrea Martínez, "reduce costes de supervisión de los accionistas a los administradores" (Gurrea, s.f). El análisis anterior demuestra la utilidad e importancia del principio de responsabilidad limitada para el fomento del emprendimiento, para el financiamiento societario y desarrollo del mercado de valores y, en última instancia, para el desarrollo económico de los Estados (Muscat, s.f). 


\section{Renuncia expresa al principio de responsabilidad limitada}

El Derecho Societario, para las compañías de capital cerrado, solamente debería estar llamado a proveer normas dispositivas para las partes, quienes podrían optar por acogerlas o, en su defecto, desviarse de las mismas cuando lo considerasen conveniente (Gurrea, s.f). La inexistencia del imperativismo normativo de la SAS se adecúa a estos parámetros, bajo el entendido que la superación de la rigidez normativa de los tipos societarios tradicionales favorece el desarrollo de las actividades operacionales de los agentes económicos (Cony, 2018).

Justamente, la superación del anacrónico imperativismo normativo en su funcionamiento es una de las dos características distintivas de la SAS. La erradicación del imperativismo normativo por instituciones societarias más flexibles se ve ejemplificada, entre otros pasajes de la ley que reconoce a esta especie societaria, en la posibilidad de los accionistas de renunciar, de manera expresa, al privilegio patrimonial que brinda el principio de responsabilidad limitada. Al respecto, la LOEI que reforma a la Ley de Compañías ha establecido, en lo medular, lo expuesto a continuación:

El o los accionistas podrán renunciar de manera expresa y por escrito al principio de responsabilidad limitada en este tipo de compañías. De mediar una renuncia expresa en tal sentido, los accionistas serán solidaria e ilimitadamente responsables por todos los actos que ejecutare la sociedad por acciones simplificadas.

Conforme fue indicado en el acápite precedente, la responsabilidad limitada impide a los acreedores de la compañía dirigir cualquier curso de acción en contra del patrimonio personal de sus socios o accionistas. Ahora bien, Gurrea Martínez considera que dicha regla general encontraría una excepción en el otorgamiento voluntario de garantías o mecanismos de aseguramiento adicionales para respaldar las obligaciones sociales (aspecto que, a decir del mencionado autor, 'suele ser frecuente en muchas sociedades cerradas') (Gurrea, s.f). 
La superación del anacrónico imperativismo normativo que tradicionalmente ha regido al Derecho Societario se fundamentaría, esencialmente, en la existencia de opt-out provisions que permitan a las partes apartarse de las reglas predispuestas por el ordenamiento jurídico, cuando dicha desviación resulte conveniente y concordante con sus intereses. Consideramos que el fomento de la libertad de contratación a través del establecimiento de normas dispositivas y flexibles para la SAS resulta, desde una perspectiva ex ante, más eficiente que la existencia de normas imperativas. En este respecto, suscribimos la opinión de Anthony Kronman (1978, p.370), quien, respecto de las default provisions, ha señalado lo siguiente:

But ex ante arguments for the efficiency of a particular legal rule assume that individuals remain free to contract around that rule, and a legal system that denies private parties the right to vary rules in this way will tend to be less efficient than a system that adopts the same rules but permits contractual variation.

Una de las opt-out provisions previstas en el marco normativo de la SAS es, justamente, la posibilidad de renunciar al principio de responsabilidad limitada. Esta alternativa confiere a los accionistas de una SAS la opción de aplicar, sin coste alguno, una solución de afianzamiento patrimonial que bien podría ser acordada por fuera de la esfera societaria, pero con altos costos de transacción, supervisión e investigación (Ayresy y Gertner, 1989, p.90). La renuncia al principio de responsabilidad limitada también podría operar mediante la celebración de un contrato de fianza, consagrado en el Código de Comercio. El artículo 662 del vigente Código de Comercio establece que:

el contrato de fianza es una convención expresa de garantía personal en virtud de la cual un tercero, ajeno al negocio principal garantizado, se compromete a responder, subsidiaria o solidariamente, del cumplimiento ante el acreedor, en lugar del deudor, que es el obligado principal, para el caso en que éste no cumpla con la obligación.

La renuncia expresa al principio de responsabilidad limitada permitiría al accionista de una SAS asumir la calidad de fiador, subsidiario o solidario, por las obligaciones de esta última. Bajo aquel 
contexto, el reconocimiento legislativo de la renuncia expresa al principio de responsabilidad limitada podría coadyuvar a una SAS, cuando fuere necesario, a obtener un mayor volumen de capital de deuda, debido a que un acreedor social, bajo este esquema, tendría la certeza que su crédito estaría asegurado con el patrimonio personal del accionista. En conclusión, el principio de responsabilidad limitada, consagrado a nivel legislativo, tendrá aplicación y protegerá a los accionistas de una SAS por regla general, a menos que ellos, de manera categórica, hubieren renunciado a la tutela conferida por este atributo societario, ya sea por intermedio de una aceptación expresa de un régimen de responsabilidad ilimitada (propio de las sociedades mercantiles personalistas), o mediante la celebración de un contrato de fianza con la sociedad.

En este respecto, la doctrina societaria más autorizada ha señalado, respecto de las default provisions, lo expuesto a continuación:

Default provisions can be supplied in a variety of ways, the choice of which affects the ease and means of 'contracting around' them. A common form of corporate law default is a statutory provision that will govern unless the parties explicitly provide an alternative" (Armour, Hansmann, Kraakman y Pargendler, 2004).

Consideramos que aquel escenario sería el que concurre respecto a la posibilidad de los accionistas de renunciar, de manera expresa, a la limitación de su responsabilidad, bajo el marco normativo de las SAS en Ecuador.

Ahora bien, entendiendo que el principio de responsabilidad limitada es uno de los pilares esenciales del Derecho Societario, la renuncia a este privilegio patrimonial operará, de manera excepcional, ante una declaración expresa de quien, de manera voluntaria, se comprometiere a responder solidariamente ante el acreedor, en lugar de la SAS (obligada principal), en caso de que ésta no cumpliere con su obligación. Por consiguiente, salvo estipulación manifiesta que estableciere inequívocamente lo contrario, el principio de responsabilidad limitada de los accionistas de una SAS deberá ser respetado, razón por la cual, en ningún caso, el afianzamiento de una 
obligación de una SAS con el patrimonio personal de uno o varios de sus accionistas podrá operar por el ministerio de la ley. De igual forma, cabe indicar que este régimen de excepción será impuesto solamente sobre el accionista renunciante. De este modo, de existir dos accionistas, la renuncia de este privilegio por parte de uno de ellos no perjudicará al otro.

Dicho esto, cabe señalar que la renuncia a la responsabilidad limitada no operaría ad infinitum, dado que el accionista renunciante podría restituir el privilegio de limitación de responsabilidad al monto de su aportación en cualquier momento, usando el mismo mecanismo que utilizó para formalizar la renuncia a este principio. Es importante matizar que la posibilidad de renunciar a la responsabilidad limitada podría ser formalizada en el estatuto social (con la inclusión de acciones con esta particularidad) o a través de un acto o contrato distinto, en el que el accionista hace uso de su derecho a renunciar, de manera expresa, a esta protección corporativa.

\section{Conclusión}

La sociedad por acciones simplificada se caracteriza por los dos siguientes atributos esenciales: Personalidad jurídica independiente y responsabilidad limitada de sus accionistas. Con relación al primer atributo, la SAS es un centro de imputación diferenciado, dotado de personalidad jurídica independiente de sus asociados. Esta separación patrimonial solamente podrá ser desconocida, previa orden judicial en aquel sentido, cuando la estructura societaria hubiere sido utilizada con proditorios fines por los asociados. Por otro lado, el segundo atributo protege a sus accionistas, quienes no estarán llamados a responder por las obligaciones sociales sino hasta por el monto de sus aportaciones. Estos dos atributos, que son los pilares esenciales del Derecho Societario, tienen plena vigencia y aplicación para las sociedades por acciones simplificadas. Dicho esto, el marco establecido por la Ley Orgánica de Emprendimiento e Innovación se caracteriza por la supresión de barreras de entrada para la constitución de las SAS. De este modo, los accionistas podrán acceder a estos derechos de una manera más expedita. Por este motivo, 
consideramos que las sociedades por acciones simplificadas, debido a la facilitación de sus procesos constitutivos, son la innovación más grande de la historia del Derecho Societario del Ecuador.

\section{Referencias Bibliográficas}

Alessandri, A. Somarriva, M. \& Vodanovic, A. Tratado de Derecho Civil: Partes Preliminar y General, Tomo II, Santiago de Chile: Ediciones Nascimiento.

Andrade, S. (2010). El Levantamiento del Velo Societario y Jurisprudencia Ecuatoriana en Romero Parducci, E. (ed), Derecho societario: Revista No. 10 EDINO.

Araujo, P. (2014). La Nueva Teoría del Delito Económico y Empresarial en Ecuador: La Responsabilidad Penal de las Personas Jurídicas y el Código Orgánico Integral Penal, Quito: Corporación de estudios y Publicaciones.

Armour, J. Hansmaan, H., Kraakman, R. \& Pargenlder, M. (2017). What is Corpoartive Law? En: Kraakman, R., Armour, J., Davies, P., Enriques, L., Hansmann, H., Hertig, G., Hopt, K., Kanda, H., Pargendler, M., Ringe, W., Rock, E. The Anatomy Of Corporate Law (OUP).

Ayres, I. \& Gertner, R., Filling Gaps in Incomplete Contrats: An Economic Theory of Default Rules, The Yale Law Journal, Vol. 99, No. 1 (Oct., 1989).

Bainbridge, S. \& Abolishing Veil Piercing (21 de julio de 2000). Available at: https://ssrn.com/abstract $=236967$

Braindige, S. \& Abolishing, V. (2011) The Corporation: A thing of power and beauty. Obtenido de https://www.professorbainbridge.com/professorbaindbridecom/2011/01/the-corporation-a-thing-of-power-and-beauty.html.

Balbín, S. (2019). Sociedad por Acciones Simplificada. Buenos Aíres: Cathedra Jurídica. 
Blumberg, P. (1993). The Multinational Challenge to Corporation Law. (OUP).

Boldó Roda, C. (2000). Levantamiento del Velo y Persona Jurídica en el Derecho Privado Español. Aranzadi Editorial No. 5, 3era Ed: Navarra, España.

Cabanellas de Torres, G. (1993). Diccionario jurídico elemental, Buenos Aires: Heliasta

Carmigniani Valencia, E. (2004). Responsabilidad de los accionistas por las deudas de la sociedad, Derecho Comercial y de las Obligaciones, Revista de Doctrina, Jurisprudencia, Legislación y Práctica, Año 37, Editorial Lexis Nexis.

Cony Etchart, R. (2018), 'Sociedad anónima simplificada: ¿Renovación o destrucción tipológica?, RSyC, FIDAS, Bs. As, 2018-1.

Davies, P.L. and Worthington, S. (2012). Gower \& Davies' Principles Of Modern Company Law (9th edn, Sweet \& Maxwell 65)

Devis Echandía, H., Nociones Generales de Derecho Procesal Civil, Bogotá

Dobson, J. (1985). El abuso de la personalidad jurídica (en el derecho privado), Buenos Aires, Depalma.

Ferran, E and Chan Ho, L. (2014). Principles Of Corporate Finance Law (2nd edn, OUP)

Grantham, R., and Rickett, C. (1998). The Bootmaker's Legacy to Company Law Doctrine. en: Rickett, C., and Grantham, R., (eds), Corporate Personality in the 20th Century, Hart Publishing, Oxford.

Gurrea Martínez, A (2018). La sociedad por acciones simplificada como paradigma de innovación jurídica: Una reflexión sobre la función social de los investigadores de Derecho a partir de la experiencia de la SAS en Colombia, Instituto Iberoamericano de Derecho y Finanzas (IIDF), Working Paper Series 2. 
Gurrea Martínez, A., y Coronel Jones, C., (coordinadores). (2019). 'Propuesta para la mejora y modernización de la legislación societaria en Ecuador', Working Paper Series 2/2019, Instituto Iberoamericano de Derecho y Finanzas.

Hannigan, B. (2016). Company Law, 4th Edition, OUP.

Hansmann, H., and Kraakman, R. (2000). 'The Essential Role Of Organisational Law' [110 YLJ 387.

Hansmann, H., Kraakman, R., and Squire, R. (2006). 'Law and the Rise of the Firm', Harvard Law Review, Vol. 119, No. 5.

Hurtado Cobles, J. (2008). La Doctrina del Levantamiento del velo Societario en España e Hispanoamérica, Atelier Libros Jurídicos, Barcelona.

Kronman, A. (1078). "Specific Performance”, 45 University of Chicago Law Review 351.

Muscat, A. (1996). The Liability Of The Holding Company For The Debts Of Its Insolvent Subsidiaries. Dartmouth Publishing Company.

Narváez García, J. (1999). Derecho Mercantil Colombiano: teoría genera de las sociedades, Bogotá: Legis.

Noboa Velasco, P. \& Ortiz-Mena, E. (21-04-2020) Elementos Característicos de las Sociedades por Acciones Simplificadas en Ecuador (Characteristic Elements of the Simplified Share Companies in Ecuador) Available at SSRN: https://papers.ssrn.com/sol3/papers.cfm?abstract_id=3582137

Noboa Velasco, P. (08-05-2018). Activos y Pasivos Sobrevenidos a la Cancelación Registral de una Sociedad Mercantil (Effects of the Cancellation of a Company on its Arising Property and Debts) Disponible en: SSRN: https://ssrn.com/abstract=3158844

Prat Rubi, J. (1985). Intervención de la persona jurídica en el juicio de quiebra. Bosch, Casa Editorial, Barcelona. 
Reyes, F. (2018). La Sociedad por Acciones Simplificada, Legis, Bogotá.

Richard, E. (2002). Personalidad Jurídica - Inoponibilidad, 20. En: Responsabilidad y Abuso en la Actuación Societaria”, Nissen, R., Pardini, M. y Vitolo, D., Editorial Ad Hoc, Buenos Aires.

Ridley, A, and Shepherd, C. (2015). Company Law Routledge.

Salgado, R. (2015). Tratado de Derecho Empresarial y Societario: Tomo II: Vol. 1: La Sociedad Anónima, Quito.

Salgado, R. (2015) Voces Conceptuales de Derecho Societario, Tomo II, Quito: Corporación de Estudios y Publicaciones.

Seijas Rengifo, T. (2007). The disregard of the legal entity (Teoría del levantamiento del velo societario)" en Revista de Derecho y Ciencia Política, UNMSM, Vol 64, ( $\left.\mathrm{N}^{\circ} 1-\mathrm{N}^{\circ} 2\right)$, Lima.

Ventoruzzo, M., et al. (2015). Comparative Corporate Law, American Casebook Series.

\section{Casos y jurisprudencia}

Arab Monetary Fund v. Hashim (No. 3) (1991)

Foss v. Hartbottle (1843) 2 Hare 461 Ch

Gaceta Judicial. Año CIII. Serie XVII. No. 10. Página 3039. (Quito, 5 de junio de 2002)

Gaceta Judicial. Año CV. Serie XVIII. No. 1. Página 133. (Quito, 28 de octubre de 2004)

Gramophone and Typewriter Co Ltd v Stanley [1908] 2KB 89 (Court of Appeal)

Macaura v Nothern Assurance Co [1925] AC 619 (House of Lords) 
Personalidad Jurídica Independiente

de la Sociedad Por Acciones Simplificada y

Responsabilidad Limitada de sus Accionistas

Salomon v A. Salomon \& Co Ltd [1897] AC 22 (House of Lords)

Standard Chartered Bank v Pakistan National Shipping Corpn and Others (Nos 2 and 4) [2003] 1 A.C. 959, 36 (Lord Hoffman)

Corte Constitucional del Ecuador Sentencia No. 22-13-IN/20, Caso No. 2213 -IN de 09 de junio de 2020. Jueza ponente: Teresa Nuques 